\title{
SNAPSHOT PICTURE OF MICROPLASTIC POLLUTION IN HALIFAX REGIONAL MUNICIPALITY
}

\author{
REBECCA TEDDIMAN* \\ Environmental Engineering Technology Program \\ Nova Scotia Community College, Halifax, NS
}

\begin{abstract}
Microplastic pollution is a pervasive problem. Many species have been found to ingest microplastics and this poses a risk to biodiversity (Fauna and Flora International, 2013). In Nova Scotia, there are few quantitative data on microplastic pollution. As quantifying microplastic pollution has only recently attained attention in Nova Scotia, no standardized methods for collection and analysis have been established. This project, although limited in scope, identified and quantified microplastic pollution on McNabs Island and Lake Banook beaches using established sampling and processing methods. The samples were evaluated using a combination of density separation, microscopic identification and RamanTM spectroscopy. This provided information to compare with other research.

Keywords: Biodiversity, Microplastic Filtration System ${ }_{\mathrm{TM}}$, Microplastic pollution, Nova Scotia
\end{abstract}

\section{INTRODUCTION}

Microplastics have gained attention in recent years with the first reports being in the early 1970's. Defined as plastic particles less than $5 \mathrm{~mm}$ in size, interest in microplastic pollution has risen recently. This is due, in part, to the global demand for plastics which has steadily increased. "Production trends, usage patterns and changing demographics will result in a further increase in the incidence of plastics debris and microplastics" (Andrady 2011). Microplastics threaten biodiversity. "It is clear that our biodiversity is under threat from competing land uses, pollution, population growth and human activities" (Government of Canada 2019). A wide range of marine life has now been found to ingest microplastic particles, including mussels, worms, fish, waterfowl and even plankton that support the whole marine food chain. Microplastics are also known

\footnotetext{
* Author to whom correspondence should be addressed: rteddiman1@gmail.com
} 
to concentrate potentially toxic chemical contaminants, which have been washed into our oceans up to one million times background levels. These chemicals include DDT and PCBs (Fauna and Flora International 2013). Beach cleanups concentrate on the removal of large plastic debris but fail to remove microplastics which can be smaller than a grain of sand. Some species are so sensitive to microplastics that they can be lethal in very small amounts (Fauna and Flora International 2013). Waterfowl can die after ingesting just 7 grams of microplastics (Sea Turtles Forever 2016).

With over $13,000 \mathrm{~km}$ of coastline and 2,300 hectares of sandy beach in Nova Scotia, a need exists to determine the quantity and concentration of microplastic contamination and pollution (where levels are causing or likely to cause adverse toxic effects) ${ }^{1}$. Many reports point to the lack of data and information on marine litter (David 2016).

The aim of the present research was to assess the scope of microplastic pollution within Halifax Regional Municipality and to determine possible remediation.

\section{METHODS}

The sample sites were chosen because of their proximity to Halifax. Variations may exist between ocean marine and freshwater environments. Three sample sites in two contrasting environments were chosen. Maugers beach on McNabs Island, in Halifax Harbour, is here after referred to as the McNabs site. As well, the beach front properties of the Banook Paddling Club and the Mic Mac Aquatic Centre on Banook lake, Dartmouth, are here after referred to as the Banook site and the Mic Mac site. McNabs Island is located in the outer part of the harbor ( $\left.44^{\circ} 36^{\prime} 34.7^{\prime \prime} \mathrm{N}, 63^{\circ} 31^{\prime} 1.9^{\prime \prime} \mathrm{W}\right)$. It has a slate and metasiltstone bedrock geology and has several drumlins.

Editor's comment - in this paper, the term "pollution" is used in the generic sense, covering both the presence of the chemical or material (contamination), in this case microplastics, and the possibility or evidence of the material causing toxic or other adverse effects (pollution). Pollution has a formal, internationally recognized definition, distinguishing it from the term "contamination" - the presence of a chemical or other agent at levels not shown to be causing harm or adverse effects. This distinction is important if one is to control the presence and levels of chemicals or other substances in the environment that may cause harm to biota, including humans. 
The island is used mostly for recreation and is accessible only by boat. Lake Banook also has a slate and metasiltstone bedrock geology and is in the heart of downtown Dartmouth (44 $44^{\prime} 51.2^{\prime \prime} \mathrm{N}$ $\left.63^{\circ} 33^{\prime} 24.9^{\prime \prime} \mathrm{W}\right)$. Again, it is used for recreation but to a greater extent, as the lake is home to three paddling clubs, has a public beach and is accessible by foot (Government of Nova Scotia 2019).

All of the sample sites are similar in that they are sandy beaches, but there is distinction between the McNabs site and the Banook/Mic Mac sites. The McNabs site is a marine environment whereas the Banook and Mic Mac sites are on the margin of a freshwater lake environment. The McNabs site is affected by tides and storm surges to a greater extent than the Banook and Mic Mac sites. As a result, a slight variation in the method of sample collection was used. While it is generally believed that microplastic pollution concentrates along the high tide mark in an intertidal marine environment, there is an absence of significant tidal energy in freshwater lake environments. Therefore, microplastic pollution along the beach in a lake environment is likely to be more uniform.

Samples were collected using Microplastic Filtration System ${ }_{\mathrm{TM}}$. This was purchased by Nova Scotia Community College from Sea Turtles Forever, Oregon USA. The method of collection was based on that by the National Oceanic and Atmospheric Administration or NOAA (Sartain et al. 2018). To avoid contamination of the samples, the equipment was treated with care. It consisted of natural materials such as organic fibers, glass and stainless steel. The clothing worn during sample collection was also made of natural fibers such as cotton.

Samples were collected in the early part of the fall, September 2019-October 2019, while the weather was still warm and dry. Transects on the beach sites were selected at random. Three transects were selected for each of the three sites. Samples collected at the McNabs site concentrated along the high tide mark, while samples collected at the Banook and Mic Mac sites were taken at the fore, back, and middle of the beaches.

The method of analysis was adapted from NOAA (Masura et al. 2015). Samples were processed using density separation method at the Nova Scotia Community College, Ivany Campus, Water Resources Laboratory. A calcium chloride solution was prepared by adding $35 \mathrm{mg} / 100 \mathrm{~mL}$ of calcium chloride to distilled water. 
The calcium chloride solution had a density of $1.2 \mathrm{~g} / \mathrm{mL}$. Quantification of the microplastics was performed using calculations of mass to mass, as well as mass to matrix $\left(\mathrm{m}^{2}\right)$ and quantity to matrix $\left(\mathrm{m}^{2}\right)$ (Table 1). The microplastics were categorized according to size and type by microscopic examination using a dissecting microscope of 40X magnification (Fig 1). Representative samples from each site were identified using Raman ${ }_{\mathrm{TM}}$ spectrometer in the Physics Laboratory, Dalhousie University (Fig 2).

\section{RESULTS AND DISCUSSION}

The quantity of microplastic pollution among the three sample sites was varied. While there was variation between sites, the values at each site were similar. The smallest amount of microplastics were found at the Mic Mac site. The highest amount was recorded at the McNabs site. Similarly, the greatest mass of microplastics was obtained from the McNabs site and the least amount of mass was from the Mic Mac site (Table 1). Consideration of both mass and amount are necessary for determining toxicity levels. "Unlike larger plastic objects, microplastics are small enough to be eaten by a wide range of marine life" (Liboiron 2015), which then bioaccumulate and possibly biomagnify, the concentrations increasing up the food web. These results indicate that the marine environment is more at risk with respect to microplastic pollution than the freshwater environment, in Halifax.

Table 1 Amount of Microplastic.

\begin{tabular}{lllcc}
\hline Location & & $\begin{array}{c}\text { Mass (microplastic) } \\
\text { / Mass (sediment) }\end{array}$ & $\begin{array}{c}\text { Mass (microplastic) } \\
\text { / Matrix }\left(\mathbf{m}^{2}\right)\end{array}$ & $\begin{array}{c}\text { Quantity (microplastic) } \\
\text { / Matrix (m })\end{array}$ \\
\hline Banook & T1 & $0.1427 .0 \mathrm{~g} / 2512.6 \mathrm{~g}$ & $0.1427 \mathrm{~g} / \mathrm{m}^{2}$ & $19 / \mathrm{m}^{2}$ \\
& T2 & $0.1456 \mathrm{~g} / 2073.0 \mathrm{~g}$ & $0.1456 \mathrm{~g} / \mathrm{m}^{2}$ & $16 / \mathrm{m}^{2}$ \\
& T3 & $0.3669 \mathrm{~g} / 2015.3 \mathrm{~g}$ & $0.3669 \mathrm{~g} / \mathrm{m}^{2}$ & $34 / \mathrm{m}^{2}$ \\
McNabs & T1 & $0.0877 \mathrm{~g} / 515.3 \mathrm{~g}$ & $0.0877 \mathrm{~g} / \mathrm{m}^{2}$ & $22 / \mathrm{m}^{2}$ \\
& T2 & $0.8334 \mathrm{~g} / 682.7 \mathrm{~g}$ & $0.8334 \mathrm{~g} / \mathrm{m}^{2}$ & $46 / \mathrm{m}^{2}$ \\
& T3 & $0.5739 \mathrm{~g} / 1434.3 \mathrm{~g}$ & $0.5739 \mathrm{~g} / \mathrm{m}^{2}$ & $41 / \mathrm{m}^{2}$ \\
MicMac & T1 & $0.0774 \mathrm{~g} / 1458.5 \mathrm{~g}$ & $0.0774 \mathrm{~g} / \mathrm{m}^{2}$ & $8 / \mathrm{m}^{2}$ \\
& T2 & $0.0807 \mathrm{~g} / 2292.0 \mathrm{~g}$ & $0.0807 \mathrm{~g} / \mathrm{m}^{2}$ & $6 / \mathrm{m}^{2}$ \\
& T3 & $0.0561 \mathrm{~g} / 1711.7 \mathrm{~g}$ & $0.0561 \mathrm{~g} / \mathrm{m}^{2}$ & $6 / \mathrm{m}^{2}$ \\
\hline
\end{tabular}


Fragments represented the highest concentration of microplastic type at all three sites accounting for $53.57 \%$ of the total (Fig 1). Fragments are secondary microplastics in that they form by breaking down over time as a result of solar radiation and wave action. Other secondary microplastics include fibers, foam and film. Primary microplastics, on the other hand, remain in their original state and include nurdles, microbeads or industrial pellets. In this study, $3.57 \%$ of the total microplastics found represented primary microplastics (Fig 1).

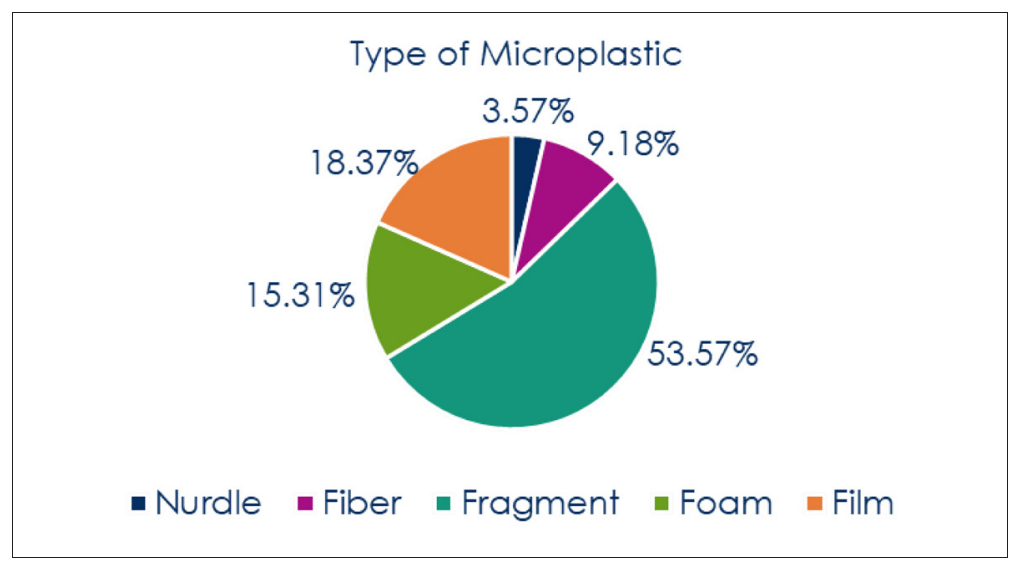

Fig 1 Microplastic Classification.

Spectroscopic analysis identified some of these fragments as polypropylene (Fig 2). Polypropylene is used in both household and industrial applications. It is a widely used commodity and often used in packaging and labelling. Results from this study indicate that over half of the microplastics found were likely to have come from consumer goods such as shopping bags, disposable water bottles and plastic food containers.

Although the spectrometer is an excellent tool for identifying the chemical composition of microplastics, there are analytical difficulties. Of the 15 samples analysed by spectrometry, only 8 came back with readable results. This was the result of microplastic particles being jagged and nonuniform rather than smooth and clean. More research is needed. "Describing, and eventually intervening in, plastic pollution requires research" (Liboiron 2016). 


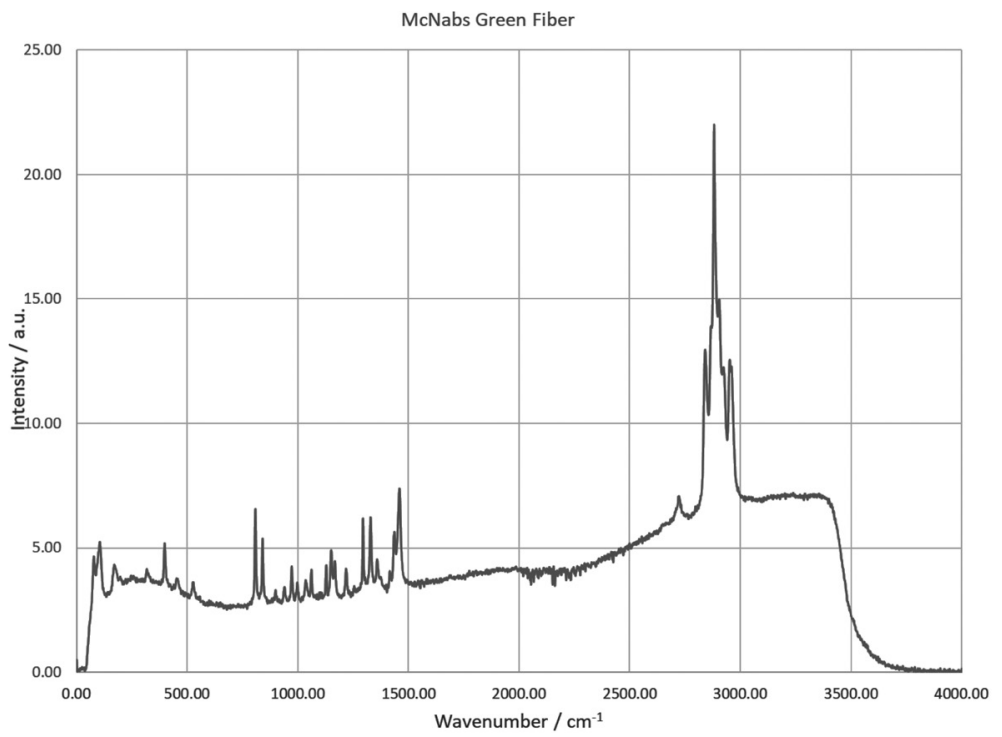

Fig 2 Spectrometry of Polypropylene

\section{CONCLUSIONS}

Microplastic pollution is a widespread problem. This project, though limited in scope, helps to fill a data gap that exists in Nova Scotia. The results obtained can now be compared with other findings. Incorporating established methods has contributed to standardization and the possibility for such comparisons.

It is recommended that further samples should be collected to assess microplastic pollution throughout Nova Scotia. This would help protect biodiversity and ensure a healthy environment for all species. Such results would also lead a focus on remediation. One way to reduce microplastic pollution in our oceans, lakes and waterways is to reduce the amount of plastics used and increase the amount recycled. Engaging the public in community science projects involving the collection and identification of microplastic pollution will also aid in identifying the scope of the problem. This would "encourage interventions that change linear plastics consumption habits" (Schnurr \& Walker 2019), while fostering accountability with respect to the impact of microplastics. 


\section{REFERENCES}

Andrady, A. (2011). Microplastics in the marine environment. Marine Pollution Bulletin 62(8): 1596-1605.

David, A.D. (2016). Marine Microplasticand Nanoplastic Litter in Nova Scotia:Confronting the Rising Tides of Plastics in our Marine Waters, Coastlines and Organisms. Halifax: Ashley Dawn David.

Fauna and Flora International. (2013). Microplastic Pollution Confirmed to be a Threat to Biodiversity. Fauna and Flora International.

Retrieved from fauna-flora.org/news/microplastic-pollution-confirmedto-be-a-threat-to-marine-biodiversity.

Government of Canada. (2018). Importance of Biodiversity. Government of Canada.

Retrieved from canada.ca/en/environment-climate-change/services/biodiversity.html.

Government of Nova Scotia. (2017). Bedrock Geology Map of Halifax Nova Scotia. Government of Nova Scotia.

Retrieved from novascotia.ca/natr/meb/download/mg/ofm/htm/ofm_2014010.asp.

Liboiron, M. (2016). "Redefining pollution and action: The matter of plastics." Journal of Material Culture 21(1): 87-110.

Masura, J., Baker, J. \& Foster, G. (2015). Laboratory methods for the analysis of microplstatics in the marine environment: recommendations for quantifying synthetic particles in water and sediment. Silver Springs: National Oceanic and Atmospheric Administration.

Sartain, M., Sparks, E. \& Wessel, C. (2018). Microplastics Sampling and Processing Guidebook. Mississippi State: Mississippi State University.

Schnurr, R.E.J. \& Walker, T.R. (2019). Should Canada's Foreign Aid Policy Help Address the Environmental Impact of Single-use Plastics? Proceedings of the Nova Scotian Institute of Science 50(1): 35-39.

Sea Turtles Forever. (2016). Microplastics. Sea Turtles Forever.

Retrieved from seaturtlesforever.org/programs/marine-plastic-debris/. 
